\title{
Retrospective Evaluation of Patients Treated with Dasatinib for Philadelphia Positive Leukemias: Turkish Experience of 16 Months*
}

\author{
Güray SAYDAM ${ }^{1}$, Ibrahim C. HAZNEDAROGLU ${ }^{2}$, Yesim TEMIZ ${ }^{3}$, Teoman SOYSAL ${ }^{4}$, \\ Gulsan SUCAK ${ }^{5}$, Murat TOMBULOGLU ${ }^{1}$, Hakan OZDOGU ${ }^{6}$, Selim YAVUZ ${ }^{7}$, Abdullah ALTINTAS ${ }^{8}$, \\ Gulsum OZET ${ }^{9}$, Zafer GULBAS ${ }^{10}$, Burhan FERHANOGLU ${ }^{4}$, Osman ILHAN ${ }^{11} * *$
}

${ }^{1}$ Ege University Faculty of Medicine Department of Hematology, İzmir

${ }^{2}$ Hacettepe University Faculty of Medicine Department of Hematology, Ankara

${ }^{3}$ BMS Pharmaceutical Company, Medical Department, Istanbul

${ }^{4}$ Istanbul University Cerrahpasa Faculty of Medicine Department of Hematology, Istanbul

${ }^{5}$ Gazi University Faculty of Medicine Department of Hematology, Ankara

${ }^{6}$ Baskent University Faculty of Medicine Department of Hematology, Adana

${ }^{7}$ Istanbul University Faculty of Medicine Department of Hematology, Istanbul

${ }^{8}$ Dicle University Faculty of Medicine Department of Hematology, Diyarbakır

${ }^{9}$ Ankara Numune Hospital Division of Hematology, Ankara

${ }^{10}$ Osmangazi University Faculty of Medicine Department of Hematology, Tokat

${ }^{11}$ Ankara University Faculty of Medicine Department of Hematology, Ankara, TURKEY

\begin{abstract}
This retrospective study was conducted on 114 CML patients with a mean treatment duration of $7.94 \pm 4.53$ months. Disease status distribution among patients was $78.1 \%$ in chronic, $7.9 \%$ in accelerated, $14 \%$ in blastic phases. The last imatinib doses in chronic, accelerated and blastic phases were 609.72 $\pm 171.29,714.29 \pm 106.90$, and 569.23 \pm 160.13 , respectively. Complete hematologic response was $66.3 \%$ and $44.4 \%$ in chronic and accelerated phases, respectively. Molecular response was evaluated by bcr/abl transcript levels in RT-PCR. Complete molecular response was $27.0 \%$ in chronic, $11.1 \%$ in accelerated and $18.8 \%$ in blastic phases. Of 99 patients 77 (77.8\%) were alive. 16th month-OS for 99 patients was $78 \%$ in Kaplan-Meier survival analysis. No adverse event was reported in $69.2 \%$ of patients, whereas disease progression and grade 1-2 myelosupression were the most frequently reported events. Most patients had complete hematological response. Dasatinib treatment was well-tolerated and resulted in favorable outcomes with mostly mild side effects.
\end{abstract}

Key Words: Dasatinib, Compassionate use program, Philadelphia positive leukemias, CML

\footnotetext{
* Data presented in this article are obtained from "Dasatinib Compessionate Use Program" that was sponsored by Bristol-Myers Squibb, Turkey.

* Bu makaledeki sonuçlar "Dasatinib için İnsani Amaçlı İlaca Erken Ulaşım” programından elde edilmiştir; bu program Bristol-Myers Squibb Türkiye tarafindan desteklenmiştir.

** On behalf of Turkish CML Working Group
} 


\section{ÖZET}

\section{Philadelphia Pozitif Lösemi Hastalarında Dasatinib Tedavisinin Retrospektif Değerlendirilmesi: 16 Aylık Ulusal Deneyim}

Bu retrospektif çalışmada $114 \mathrm{KML}$ hastasında ortalama tedavi süresi $7.94 \pm 4.53$ aydı. Hastalar arasında hastalık durum dağılımı \%78.1 kronik, \%7.9 hızlanmış, \%14 blastik faz şeklinde idi. Kronik, hızlanmış ve blastik fazlarda son imatinib dozları sırası ile $609.72 \pm 171.29,714.29 \pm 106.90$ ve $569.23 \pm 160.13$ idi. Kronik ve hızlanmış fazlarda tam hematolojik cevap sırası ile \%66.3 ve \%44.4 olarak bulundu. Moleküler cevap RT-PCR'da bcr/abl transcript seviyeleri ile değerlenmişti. Tam moleküler cevap kronik fazda \%27.0, hızlanmış fazda \%11.1 ve blastik fazda \%18.8 idi. Toplam 99 hastanın 77'si (\%77.8) hayatta kalmıştı. Kaplan-Meier sağkalım analizinde 99 hastanın 16. ay genel sağkalım değeri $\% 78$ idi. Hastaların \%69.2'sinde advers olay bildirilmezken, hastalık ilerlemesi ve evre 1-2 miyelosupresyon en sik bildirilmiş olan advers olaylardı. Hastaların çoğu tam hematolojik cevaba sahipti. Buna göre, dasatinib tedavisinin iyi tolere edildiği ve çoğunlukla hafif yan etkilerle birlikte olumlu çıktılar sağladığı söylenebilir.

Anahtar Kelimeler: Dasatinib, İnsani amaçlı ilaca erken erişim programı, Philadelphia pozitif lösemi, KML

\section{INTRODUCTION}

Chronic myeloid leukemia (CML) has been defined as the malignant clonal disease of hematopoietic stem cells resulting in detection of increased numbers of myeloid cells, erythroid cells and platelets in peripheral blood, and myeloid hypercellularity in bone marrow. ${ }^{1}$ It is very well documented that the expression of constitutively activated tyrosine kinase, which is a product of BCR-ABL, is underlying reason for CML phenotype. ${ }^{2,3}$ The reciprocal translocation between chromosomes 9 and 22 produces the shortened 22q known as the Philadelphia chromosome $(\mathrm{Ph})$ and the new fusion gene is called as BCR-ABL fusion gene. ${ }^{4}$ The typical clinical presentation of CML is seen in 3 different clinical phases; chronic phase (CP), accelerated phase (AP) and blastic phase (BP). ${ }^{5}$ Without appropriate treatment, newly diagnosed chronic phase CML patients would eventually progress to accelerated and finally blastic phase. BP is of mainly myeloid phenotype in almost two third of patients and of lymphoid phenotype in most of the remaining patients. ${ }^{6} \mathrm{BP}$ of the disease in all forms have poor prognosis with overall survival of 3 to 6 months. ${ }^{7}$ Most of the patients have been diagnosed in chronic phase. ${ }^{8}$

Although the $\mathrm{Ph}$ chromosome and BCR-ABL transcript positivities have been major laboratory determinants of CML, this phenomenon is also detectable in acute lymphoblastic leukemia (ALL). ALL is the most common type of leukemia in children; ALL is also diagnosed in adults with less frequency and incidence, and has a second peak over the age of 70 years. ${ }^{9}$ Chromosomal abnormalities have been documented in the course of ALL, and approximately $20-30 \%$ of adult ALL patients present with $\mathrm{Ph}$ abnormality. ${ }^{10}$ The $\mathrm{Ph}$ positivity increase with age, being greater in older patients compared to young adults and children. ${ }^{11}$ Regardless of the age, $\mathrm{Ph}(+) \mathrm{ALL}$, whether in adult or in children, has poorer prognosis compared to patients without this chromosomal abnormality. ${ }^{12}$

The use of imatinib in the treatment of $\mathrm{Ph}(+)$ leukemias has been a milestone in the treatment of hematological malignancies. The tyrosine kinase activity of BCR-ABL is the main therapeutic target of imatinib that is the first tyrosine kinase inhibitor (TKI) used in the treatment of CML. It also inhibits the activity of c-kit, ARG and platelet derived growth factor receptors. ${ }^{13}$ A large phase III randomized trial, known as IRIS, has provided the clinical and scientific background for the use of imatinib in the treatment of $\mathrm{Ph}(+)$ leukemias. ${ }^{14}$ At a median follow-up of 19 months, the rate of complete cytogenetic response (CCyR) in the imatinib-treated patients was $94 \%$ compared with a CCyR of $8.5 \%$ achieved by patients on IFN-alpha and cytarabine. According to the 5-years results of IRIS study, only $68 \%$ of the patients in CCyR still remained on imatinib therapy. ${ }^{15}$

The large use of imatinib in the treatment of $\mathrm{Ph}(+)$ leukemias have also created a new terminology like imatinib-intolerance and imatinib-resistance, and molecular pathogenesis of this new definitions have been clearly described in many studies..$^{16-18}$ The main mechanism for imatinib resistance has been clearly documented as the mutations occurred under the treatment of imatinib. ${ }^{8}$ These definitions and the clinical results of either intolerance or resis- 


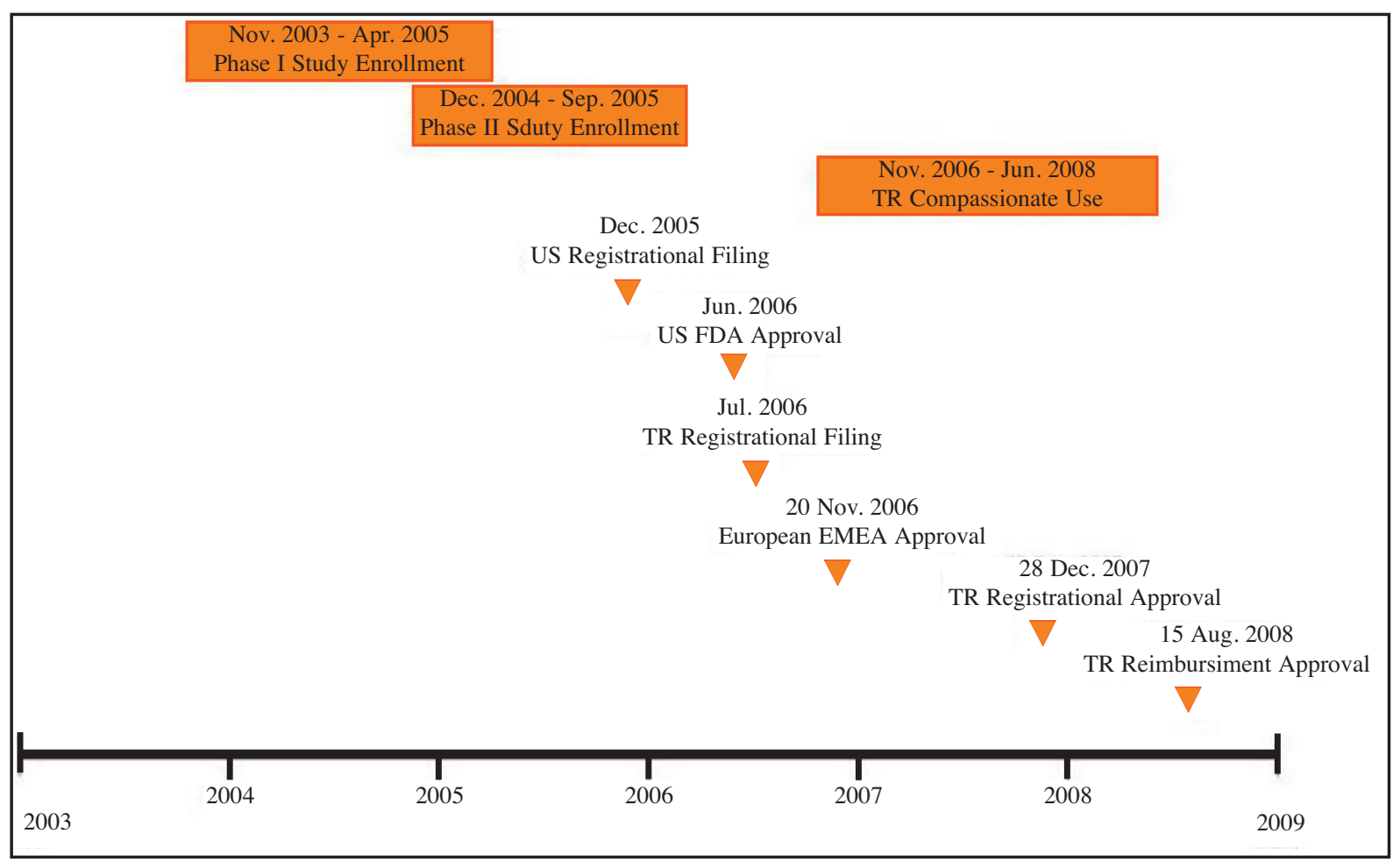

Figure 1. The developmental stages and timeline, and the clinical introduction of dasatinib

tance have implemented the need for new TKIs. Dasatinib is an SRC-family TKI that is structurally different from imatinib. ${ }^{19}$ It has activity against many of the mutant forms of BCR-ABL, which are resistant to imatinib and this activity has resulted in the use of dasatinib in the treatment of CML and $\mathrm{Ph}$ (+) ALL. Its ability to bind both the inactive and active forms of BCR-ABL provides broader spectrum. ${ }^{20}$ The Phase II START (SRC/ABL Tyrosine kinase inhibition Activity Research Trials of dasatinib) program contains the largest and most comprehensive study of dasatinib in the treatment of $\mathrm{Ph}-$ positive leukemias to date. ${ }^{21-25}$ It included 5 separate arms $(\mathrm{C}, \mathrm{A}, \mathrm{B}, \mathrm{L}$ and $\mathrm{R})$ that evaluated the effects of dasatinib in patients with CML or Ph (+) ALL at different stages who were classified as imatinib-resistant or -intolerant. START-C, A, B and L studies were designated as open-label, nonrandomized and with non-comparative arms and in these trials, dasatinib treatment was started with $70 \mathrm{mg}$ BID. The dose could be escalated up to 90 or $100 \mathrm{mg}$ BID in case of poor initial response or decreased to 50 or $40 \mathrm{mg}$ BID in the patients with persistent drug-related toxicity. ${ }^{26}$ The results of START Phase
II trials showed that dasatinib was an effective treatment regimen in CML and Ph+ALL diseases and reported adverse events during dasatinib treatment were relatively low and tolerable. Dasatinib has been approved by FDA in 2006 for the use as a single agent in the treatment of adults with CML (CP, AP or BP [myeloid or lymphoid]) or with $\mathrm{Ph}$-positive acute lymphoblastic leukemia (ALL), with resistance or intolerance to prior therapy, including imatinib (Figure 1). ${ }^{27}$ In Turkey, due to quite long registration and reimbursement procedures and local regulations, dasatinib was not on the market until 15 August 2008. However, certain numbers of patients have shown imatinib resistance or intolerance during or before this period. Compassionate use programs (CUP) are intended to facilitate the patient access for unmet needs during registration and reimbursement procedures. BMS has started a CUP to provide dasatinib to the patients who were defined as the imatinib-resistant or -intolerant by the primary physician according to the international and largely accepted guidelines at the second part of 2006. By using this compassionate use program, consistent policy across participating centers in Tur- 
key was established and applied. After the marketing authorization of dasatinib, the program was ended.

The aim of this report was to analyze and present the characteristics and the general results of dasatinib treatment in patients with $\mathrm{Ph}(+)$ leukemia and treated with dasatinib under compassionate use program in Turkey.

\section{MATERIALS AND METHODS}

\section{Patients}

The primary objective of this compassionate use program was to provide access to dasatinib to as many patients as possible during the application period across in all region of Turkey. Between November 2006 and April 2008114 patients from 27 different centers across Turkey were enrolled to CUP by single patient based application. This program was not performed either as a part of any clinical trials or in the setting of clinical trial. The clinical and laboratory status of the patients was followed-up by their primary physicians. The criterions for the start of the dasatinib treatment were based on the NCCN and ELN CML guidelines. The primary physicians of the patients were asked to fill out the forms containing the demographic data of the patients, the disease status, and the certain indication(s) for dasatinib requirement under the guidance of current guidelines. These forms were signed by the physicians and sent to BMS center. Patients were also required to give written informed consent. They were also informed and educated for the potential outcomes and side effects which could be detected under dasatinib treatment.

\section{Patients' Inclusion}

Patients $\geq 18$ years with the following disease characteristics were defined as the eligible for the dasatinib treatment under the CUP: dasatinib is indicated for the treatment of adults with chronic, accelerated, or myeloid or lymphoid blast phase chronic myeloid leukemia (CML) with resistance or intolerance to prior therapy including imatinib. Dasatinib is also indicated for the treatment of adults with Philadelphia chromosome-positive acute lymphoblastic leukemia $(\mathrm{Ph}+\mathrm{ALL})$ with resistance or intolerance to prior therapy

\section{Patients' Exclusion}

Patients were excluded if they had prior history of pleural effusion with any reason, ECOG performance status $>3$, grade 3-4 cardiac disease as defined by the New York Heart Association criteria, serum creatinine, liver transaminase, or bilirubin above the upper limit of normal range, females with pregnancy, serious concomitant medical condition, history of noncompliance to prior medical approaches.

\section{Treatment}

Dasatinib (Sprycel, BMS) was supplied as 50-and $20 \mathrm{mg}$ tablets. CML-CP, AP, BP, and Ph (+) ALL patients started to use dasatinib at a dose $70 \mathrm{mg}$ BID. If the patient was evaluated as unresponsive based on the published and accepted current literature, dose escalation up to $200 \mathrm{mg} /$ day was allowed. In case of any grade 3-4 adverse events reported by primary physicians, dose reduction from 70 $\mathrm{mg} \mathrm{BID}$ to $50 \mathrm{mg}$ BID was applied. Other dose and treatment modifications were performed if needed for each case by using the data from clinical phase studies and large trials.

Dasatinib treatment with was continued until death, disease progression under dasatinib therapy (for CML-CP patients), development of serious toxicity, lack of efficacy proven clinically and with laboratory tests such as cytogenetic and molecular methods, or whenever dasatinib became commercially available and the patient was able to continue therapy via prescription.

\section{Evaluation of the Patients}

Patients were evaluated according to the age, gender, median time from the diagnosis, the reasons for dasatinib treatment, and stage of the disease, last imatinib doses, last treatment status with dasatinib, adverse events under dasatinib treatment, and response status to dasatinib treatment retrospectively.

The independent Clinical Research Organization (CRO) company was hired to fill out the questionnaire forms containing the each section above mentioned which are prepared by the Turkish CML Study Group. CRO has visited all centers where the patients were enrolled to the program and filled these forms based on the patients' files. Additionally, serious adverse event forms reported by primary 
Table 1. Summary of CML disease phases at dasatinib treatment inititation and average dasatinib dose with treatment duration.

\begin{tabular}{|c|c|c|c|c|c|}
\hline $\begin{array}{l}\text { Disease } \\
\text { phase }\end{array}$ & $\begin{array}{l}\text { Frequency } \\
(\%)\end{array}$ & $\begin{array}{l}\text { Valid } \\
(\%)\end{array}$ & $\begin{array}{l}\text { Cumulative } \\
\text { percentage }\end{array}$ & $\begin{array}{l}\text { Average dose } \\
(95 \% \mathrm{CI}, \mathrm{mg})\end{array}$ & $\begin{array}{l}\text { Treatment duration } \\
\text { with average dose } \\
(95 \% \mathrm{CI}, \text { month })\end{array}$ \\
\hline Chronic & $89(78.1)$ & 78.1 & 78.1 & $\begin{array}{l}103.06 \\
(98.6-107.6)\end{array}$ & $\begin{array}{l}17.5 \\
(12.3-22.7)\end{array}$ \\
\hline Accelerated & $9(7.9)$ & 7.9 & 86.0 & $\begin{array}{l}120.37 \\
(98.6-142.1)\end{array}$ & $\begin{array}{l}8.38 \\
(2.9-13.9)\end{array}$ \\
\hline Blastic & $16(14.0)$ & 14.0 & 100.0 & $\begin{array}{l}123.33 \\
(115.0-131.7)\end{array}$ & $\begin{array}{l}11.07 \\
(6.8-15.3)\end{array}$ \\
\hline
\end{tabular}

physicians and the application forms required for the enrollment to the program as a routine base were used for further patients' information.

\section{Endpoints}

The primary endpoint of this program was to provide patient access to dasatinib before registration, and to determine hematological response rate, the number of treatment related adverse events and treatment discontinuation rates. Also, dose modifications, disease status under dasatinib treatment, cytogenetic and molecular responses was analyzed and evaluated according to the available patient data.

\section{Statistical Analysis}

All the statistical analyses were performed by using the data obtained from the patients' files recorded by primary physicians. Special form was designed to summarize the required data and completed by independent CRO. Any patient who received at least one dose of dasatinib was included into evaluation. Demographics, diseases status at baseline, time from diagnosis, duration of prior treatment, the reasons for switching therapy to dasatinib, and the last imatinib doses were summarized for all leukemic patients Additionally, the last disease status, mortality rates, discontinuation rates, and the reported adverse events, dose modifications were also presented.
Time to progression (TTP) was defined as the time between starting the drug and either discontinuation of drug for any reason or death. Overall survival (OS) was defined as the time period between the entry of therapy to death because of any reason as well as any death reported after drug stopped. TTP and OS were performed by using Kaplan-Meier method.

\section{RESULTS}

Between November 2006 and April 2008, a total number of 114 patients were enrolled into CUP from 27 centers of Turkey. All patients received at least one dose of drug. All patients were evaluated for study outcomes. 114 patients were enrolled to dasatinib study and $57.89 \%$ of the patients (66 patients) are male. Mean age for male, female and all patients are $46.53 \pm 14.57,48.5 \pm 14.19$ and $47.37 \pm 14.38$, respectively. The youngest subject on dasatinib is 18 years old and oldest is 80 . Mean time from diagnosis to dasatinib treatment was calculated as $73.96 \pm 52.65$ (1-288) months. Before starting the dasatinib treatment, mutational analyses could not be performed in most of the cases. Table 1 denotes disease phases of patients with CML at dasatinib treatment initiation and dasatinib average dose and duration. Table 1 indicated that $78.1 \%, 7.9 \%$ and $14 \%$ of patients with CML were in chronic, accelerated phase and blastic phase, respectively at dasatinib treatment initiation. The reasons of switch from imatinib to dasatinib were 
Table 2. Summary of hematologic response rates according to CML phases.

\begin{tabular}{llllll}
\hline $\begin{array}{l}\text { CML } \\
\text { Phases }\end{array}$ & $\begin{array}{l}\text { Complete } \\
\text { Response }\end{array}$ & $\begin{array}{l}\text { Partial } \\
\text { Response }\end{array}$ & $\begin{array}{l}\text { No } \\
\text { Response }\end{array}$ & Exitus & Unknown \\
\hline Chronic & $59(66.3 \%)$ & $3(3.4 \%)$ & $3(3.4 \%)$ & $14(15.7 \%)$ & $10(11.2 \%)$ \\
Accelerated & $4(44.4 \%)$ & $0(0.0 \%)$ & $1(11.1 \%)$ & $4(44.4 \%)$ & $0(0.0 \%)$ \\
Blastic & $6(37.5 \%)$ & $0(0.0 \%)$ & $0(0.0 \%)$ & $8(50.0 \%)$ & $2(12.5 \%)$ \\
\hline
\end{tabular}

classified as progression under imatinib (41.2\%), resistance $(33.3 \%)$ and intolerance to imatinib $(16 \%)$ and combination of these $(8 \%)$. The last imatinib dose prior to initiation of dasatinib was $609.7 \pm 171.3(300-1000) \mathrm{mg} /$ day, $714.3 \pm 106.9$ (600-800) and 569.2 \pm 160.1 (400-800) for CP, AP and $\mathrm{BP}$ patients, respectively. The highest average dose was $123.3 \mathrm{mg} / \mathrm{d}$ in blastic phase and lowest was $103.1 \mathrm{mg} / \mathrm{d}$ in chronic phase. Patients in chronic phase have the longest period with 17.5 months in average (Table 1). The hematologic response status of CML patients was categorized based on phases. Table 2 showed that $66.3 \%$ of patients in chronic phase and $44.4 \%$ in accelerated phase have complete hematologic response (CHR) and 50\% death rate in blastic phase. Cytogenetic analysis results could not be obtained from all patients due to different enrollment date to the CUP. Molecular response (MR) status was evaluated based on bcr/abl transcript levels by using RT-PCR. $27.0 \%$ of the cases in chronic, $11.1 \%$ in accelerated and $18.8 \%$ in blastic phase have complete molecular response (Table 3 ) which is defined disappearance of bcr-abl transcripts. Blood samples were obtained from all patients and analyzed for laboratory evaluations. While the most adverse reaction was hematological during the dasatinib treatment, fluid retention including pleural edema, infectious problems, gastrointestinal side effects, skin problems and neurological side effects were also observed. Table 4 showed the summary of treatment-related adverse events occurring during the dasatinib treatment. Thrombocytopenia is the most prominent hematological side effects with the ratio of $24.3 \%$, while leucopenia and neutropenia was also reported with $20.2 \%$. Pleural effusion, which is the most common non-hematological side effect, was detected as $8.5 \%$ of total side effects. Of 114 patients, 83 patients' data were eligible for progression analysis. While disease stabilization or remission were obtained in 76 of 83 patients (91.6\%), progression was determined in 7 of 83 patients $(8.4 \%)$ and progression time was 5 to 27 months (Figure 2). Twenty two of 114 patients died during the follow-up period. Of those, 13 patients (59\%) died due to progressive disease, 3 patients died due to severe infections

Table 3. Philadelphia chromosome status of CML subjects

\begin{tabular}{lllll}
\hline \multirow{2}{*}{ CML Phases } & \multicolumn{3}{c}{ Changes in Philadephia chromosome } \\
\cline { 2 - 5 } & Disappearance & Decrease & No Change & Unknown \\
\hline Chronic & $24(27.0 \%)$ & $13(14.6 \%)$ & $8(9.0 \%)$ & $44(49.4 \%)$ \\
Accelerated & $1(11.1 \%)$ & $2(22.2 \%)$ & $0(0.0 \%)$ & $6(66.7 \%)$ \\
Blastic & $3(18.8 \%)$ & $0(0.0 \%)$ & $2(12.5 \%)$ & $11(68.8 \%)$ \\
\hline
\end{tabular}

NOTE: Above table shows the Philadelphia chromosome status of CML subjects which are studied by RT-PCR and/or conventional cytogenetic remission. Philadelphia chromosome of CML subjects have been assessed via detection of bcr/abl positivity with RT-PCR. According to the table, \%27.0 of subjects in chronic phase showed disappearance considering Philadelphia chromosome status. Rest of the frequencies and percentages are as shown in the table. 
Table 4. Summary of treatment-related adverse events reported during the dasatinib treatment

\begin{tabular}{llll}
\hline & \multicolumn{3}{c}{ Phases of CML } \\
\cline { 2 - 4 } Adverse Events & Chronic & Accelerated & Blastic \\
\hline Anemia & $19(20.2 \%)$ & $2(22.2 \%)$ & $2(15.4 \%)$ \\
Leucopenia / Neutropenia & $19(20.2 \%)$ & $2(22.2 \%)$ & $2(15.4 \%)$ \\
Pancytopenia & $3(3.2 \%)$ & $0(0 \%)$ & $0(0 \%)$ \\
Thrombocytopenia & $23(24.5 \%)$ & $1(11.1 \%)$ & $4(30.8 \%)$ \\
Cytopenia in total & $64(68 \%)$ & $5(55 \%)$ & $8(61.5 \%)$ \\
Pleural effusion & $8(8.5 \%)$ & $3(33.3 \%)$ & $3(23.1 \%)$ \\
Fluid retention/ Edema & $4(4.3 \%)$ & $1(11.1 \%)$ & $0(0 \%)$ \\
Locomotor & $2(2.1 \%)$ & $0(0 \%)$ & $0(0 \%)$ \\
Neurologic & $2(2.1 \%)$ & $0(0 \%)$ & $0(0 \%)$ \\
Infection & $3(3.2 \%)$ & $0(0 \%)$ & $0(0 \%)$ \\
Skin & $6(6.4 \%)$ & $0(0 \%)$ & $0(0 \%)$ \\
GIS & $5(5.3 \%)$ & $0(0 \%)$ & $2(15.4 \%)$ \\
\hline
\end{tabular}

and sepsis. Other reasons for death are classified as pancytopenia, chronic renal failure, relapsed disease, and graft rejection after allogeneic transplantation. No patients died because of any side effects of treatment. All calculations were based on 99 patients who were eligible for survival analysis. Survival analysis is based on Kaplan-Meier survival function, which takes into account the exitus and li- ving subjects. The date of dasatinib initiation for all subjects, date of exitus for exitus subjects and the treatment period of living subjects are considered here. 77 of 99 patients $(77.8 \%)$ were alive and 22 (\%22.2) died. Figure 3 showed that 16 th month-OS for 99 patients was $78 \%$ according to Kaplan-Meier survival analysis.
Time to progression

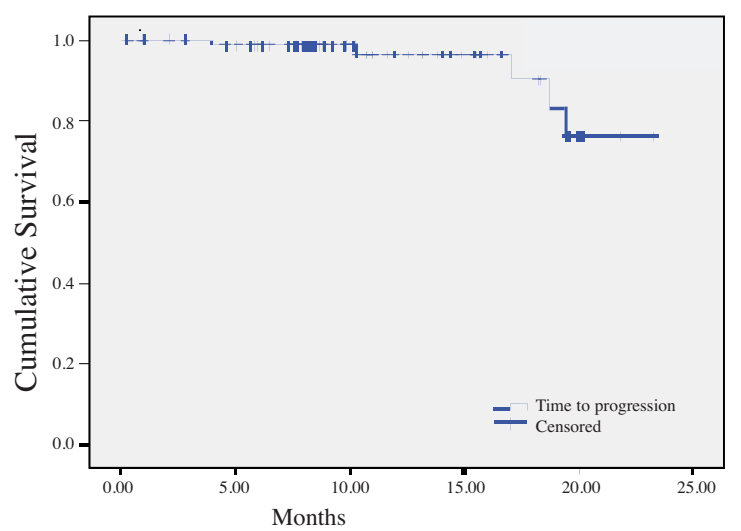

Figure 2. Time to progression with dasatinib treatment (in months) 


\section{DISCUSSION}

We hereby summarized the result of dasatinib CUP in Turkey regarding the effectiveness, side effects and therapy results in patients with $\mathrm{Ph}(+)$ leukemias. By the acceptance of 114 patients with 16 months time period, dasatinib CUP reached to the first aim, which was defined as the delivery of the drug to the patients. Since this program was open to patients with $\mathrm{Ph}(+)$ leukemias and with appropriate criteria described previously, this explained the heterogeneity of the group. This program was not a clinical trial and also was not a part of any clinical trial. The interpretation of the results of the CUP should take into account that this program has provided limited efficacy and safety data since the length of follow-up was limited by the date when dasatinib was commercially available. Despite this limitation, the results of OS and TTP are found to be promising. There has not been any publication on dasatinib evaluating the results of patients' access program up to now. Although Capdeville et al. published the results of international expanded access program of imatinib, the designation and contents of that publication is completely different from our study. ${ }^{28}$ Since the primary aim and the endpoint have not been defined as the determination of either molecular or cytogenetic responses, the clinicians were asked to provide if they have available data. However, the central authorities and the BMS Company requested the clinicians to fill the adverse event forms appropriately. One of the major endpoint for our study was described the hematological response rate at the end of the CUP. The CHR was calculated as $66.3 \%$ in our CP-CML patients. In START-C study, dasatinib was evaluated in 387 CP-CML patients and these patients were followed-up for a median of 15.2 months. ${ }^{21} \mathrm{CHR}$ was found to be as $91 \%$ in patients treated with dasatinib in START-C clinical study. The CHR in our CUP program was relatively lower compared to START-C study, but the heterogeneity of our patients could explain this difference. Moreover, similar difference can be detected also in molecular response status. Although the cytogenetic response status was evaluated and found to be as 59\% MCyR in START-C study, CMR was found to be as $27.0 \%$ in our CP- CML patients treated under CUP. Although the molecular response rate does not directly reflect the cytogenetic response rate, it is highly possible to say that the response rate was lower in our CUP. However, as mentioned before, the heterogeneity of patients and also the heterogeneity of the laboratories which performed these analyses could be the potential reason for this difference. Also, CUP is not designated as the clinical study and the results don't illustrate the results of clinical study. In our report, CHR was found to be as $44.4 \%$ in patients with AP-CML patients. In START-A study, the effectiveness of dasatinib was evaluated in patients with AP-CML patients and CHR was obtained in $45 \%$ of patients. ${ }^{23}$ The CHR in our patients with AP- CML patients was similar with START-A study. However the number of patients in our CUP is relatively less than the START-A study.

Most of the reported side effects under treatment with dasatinib are mild-to-moderate. In almost all of the phase II clinical trials, various degrees of side effects were reported and the most common drug-related toxicities were fluid retention including pleural effusion, diarrhea, skin rash, headache, hemorrhage fatigue, nausea and dyspnea. ${ }^{29}$ Pleural effusion, edema and other type of fluid retention events were seen with different ratios during dasatinib clinical trials. Especially the edema occurred during dasatinib treatment was grade 1-2 and was successfully managed with diuretics. It was reported as $4 \%$ in our chronic-phase CML patients which is similar to results obtained from other studies. Pleural effusion, which is accepted as the most troublesome side effect of dasatinib, was detected with the ratio of $8.5 \%$ in our patients with chronicphase CML. Grade 3-4 pleural effusions were reported with the ratio of 4-15\%, and the incidence of any grade of pleural effusions were $13-27 \%$ in START studies..$^{21-25}$ Other fluid retention events were uncommon. Edema, pleural effusions and other fluid retention events could be successfully manipulated by dose interruption, reduction or modifications of the treatment schedules. Corticosteroids may be helpful, but no steroid need was reported in our patients. Since these patients have hematological malignancies and prior treatments, it is highly expected to see some level of hematologic toxicity. Treatment with dasatinib may result in grade 3-4 thrombocytopenia, neutropenia and anemia. Myelosupression as an anticipated therapeutic effect of dasatinib could be detected in patients with advanced stage of CML or Ph+ ALL. Hopefully, it is re- 
versible with dose modifications or short term interruptions. In our study, any degree of bone marrow suppression as cytopenia were reported with the ratio of $55-68 \%$ in patients treated with dasatinib. However, none of the patients died because of hematological side effects and all of these events were reversible by interventions as abovementioned. The survival analysis of our patients has some promising results. According to Kaplan-Meier analysis of our available 99 patients, OS of our group $78 \%$ for the patients treated with dasatinib under CUP at 16th month. Since the OS was estimated $66-82 \%$ in START studies, our results could be accepted similar to these clinical studies.

Optimal management of imatinib resistant or intolerant $\mathrm{Ph}+\mathrm{CML}$ is a growing problem in last five years. ${ }^{30-32}$ Dasatinib has been the first tyrosine kinase inhibitor approved for use in CML and Ph+ ALL in patients resistant or intolerant to imatinib. In conclusion, evaluable results from Turkish dasatinib CUP were accordingly with clinical trial results previously reported. This CUP is not a clinical trial, therefore the patients treated with dasatinib was heterogeneous. As enrollment date to the CUP is different for each patient, variable treatment durations may possibly affect response rates and definition. However, dasatinib treatment in Turkish patients with CML was well tolerated and resulted in favorable outcomes with only mild side effects in most cases during the period of observation of patients with accessible data so far.

\section{ACKNOWLEDGEMENTS}

The results presented here are from dasatinib compassionate use program and supported by Bristol-Myers Squibb Turkey. The following physicians participated in the Program: Munci Yagci, Emel Gurkan, Semra Paydas, Gunhan Gurman, Nahide Konuk, Mehmet Sonmez, Ridvan Ali, Hayri Ozsan, Orhan Ayyildiz, Osman I. Ozcebe, Gulsum Ozet, Abdullah Hacihanefioglu, Ali Unal, Serdar B. Omay, Seniz, Ongoren, Zeynep Aki, Akin Uysal, Ismail Sari, Mehmet Ali Ozcan, Oktay Bilgir, Ahmet Durmus, Berksoy Sahin, Sinan Yavuz, Aynur U. Bilgin, Sema Karakus, Zubeyde N. Ozkurt, Funda Ceran, Meltem Ayli, Evren Ozdemir, Suleyman Dincer, Songul Serefhanoglu, Hakan Goker, Mustafa Cetiner, Yahya Buyukasik, Nilgun Sayinalp, Emel Gonullu, Sami Karti, Sibel K. Hacioglu, Mehmet Calan, Fahir Ozkalemkas, Leylagul Kaynar, Simten Dagdas, Can Boga, Ismet Aydogdu, Pervin Topcuoglu.

\section{REFERENCES}

1. Sawyers CL. Chronic myeloid leukemia. N Engl J Med 340: 1330-1340, 1999.

2. Daley GQ, Van Etten RA, Baltimore D. Induction of chronic myelogenous leukemia in mice by the P210bcr/abl gene of the Philedelphia chromosome. Science 247: 824-830, 1990.

3. Lugo TG, Pendergrast AM, Muller AJ, et al. Tyrosine kinase activity and transformation potency of bcr-abl oncogene products. Science 247: 1079-1082, 1990.

4. Rowley JD. Letter: a new consistent chromosomal abnormality in chronic myelogenous leukemia identified by quinacrine fluorescence and Giemsa staining. Nature 243: 290-293, 1973.

5. Sokal JE, Baccarani M, Russo D, et al. Staging and prognosis in chronic myelogenous leukemia. Semin Hematol 25: 49-61, 1988.

6. Kurzrock G, Gutterman J, Talpaz M. The molecular genetics of Philedelphia chromosome-positive leukemias. N Engl J Med 319: 990-998, 1988.

7. Sacchi S, Kantarjian HM, O'Brien S, et al. Chronic myelogenous leukemia in nonlymphoid blastic phase: analysis of the results of first salvage therapy with three different treatment approaches for 162 patients. Cancer 86: 2632-2641, 1999.

8. Steinberg M. Dasatinib: A tyrosine kinase inhibitor for the treatment of chronic myelogenous leukemia and Philedelphia chromosome-positive acute lymphoblastic leukemia. Clin Ther 29: 2289-2308, 2007.

9. Hoelzer D, Gokbuget N. Recent approaches in acute lymphoblastic leukemia in adults. Crit Rev Oncol Hematol 36: 49-58, 2000.

10. Piccaluga PP, Paolini S, Martinelli G. Tyrosine kinase inhibitors for the treatment of Philedelphia chromosome-positive adult acute lymphoblastic leukemia. Cancer 110: 1178-1186, 2007.

11. Ottmann OG, Wassmann B. Treatment of Philadelphia chromosome-positive acute lymphoblastic leukemia. Hematology Am Soc Hematol Educ Program 118-122, 2005.

12. Onciu M, Bueso-Ramos C, Medeiros J, et al. Acute lymphoblastic leukemia in elderly patients: The Philadelphia chromosome may not be a significant adverse prognostic factor. Am J Clin Pathol 117: 716-720, 2002.

13. Deininger M, Buchdunger E, Druker BJ. The development of imatinib as a therapeutic agent for chronic myeloid leukemia. Blood 105: 26402653, 2005. 
14. O'Brien SG, Guilhot F, Larson RA, et al. Imatinib compared with interferon and low-dose cytarabine for newly diagnosed chronic-phase chronic myeloid leukemia. N Engl J Med 348: 994 1004, 2003.

15. Druker BJ, Guilhot F, O'Brien SG, et al. Fiveyear follow-up of patients receiving imatinib for chronic myeloid leukemia. N Engl J Med 355: 2408-2417, 2006.

16. Hochhaus A, Kreil S, Corbin AS, et al. Molecular and chromosomal mechanisms of resistance to imatinib (STI571) therapy. Leukemia 16: 2190-2196, 2002.

17. Soverini S, Martinelli G, Rosti G, et al. ABL mutations in late chronic phase chronic myeloid leukemia patients with up-front cytogenetic resistance to imatinib are associated with a greater likelihood of progression to blast crisis and shorter survival: a study of GIMEMA Working Party on Chronic Myeloid Leukemia. J Clin Oncol 23: 4100-4109, 2005.

18. Gorre ME, Mohammed M, Ellwood K, et al. Clinical resistance to STI-571 cancer therapy caused by BCR-ABL gene mutation or amplification. Science 293: 876-880, 2001.

19. Bradeen HA, Edie CA, O'Hare T, et al. Comparison of imatinib mesylate, dasatinib (BMS354825) and nilotinib (AMN107) in an N-ethyl$\mathrm{N}$ nitrosourea (ENU9- based mutagenesis screen: High efficacy of drug combinations. Blood 108: 2332-2338, 2006.

20. Talpaz M, Shah NP, Kantarjian H, et al. Dasatinib in imatinib-resistant Philadelphia chromosome-positive leukemias. N Engl J Med 354: 2531-2541, 2006.

21. Hochhaus A, Kantarjian HM, Baccarani M, et al Dasatinib induces notable hematologic and cytogenetic responses in chronic phase chronic myeloid leukemia after failure of imatinib therapy. Blood 109: 2303-2309, 2007.

22. Ottmann O, Dombret H, Martinelli G, et al. Dasatinib induces rapid hematologic and cytogenic responses in adult patients with Philadelphia chromosome-positive acute lymphoblastic leukemia with resistance or intolerance to imatinib: interim results of a phase 2 study. Blood 110: 2309-2315, 2007.

23. Guilhot F, Apperley JF, Kim DW, et al. Dasatinib induces significant hematologic and cytogenetic responses in patients with imatinib resistant or -intolerant chronic myeloid leukemia in accelerated phase. Blood 109: 4143-4150, 2007.

24. Cortes J, Rousselot P, Kim DW, et al. Dasatinib induces complete hematologic and cytogenetic responses in patients with imatinib-resistant or -intolerant chronic myeloid leukemia in blast crisis. Blood 109: 3207-3213, 2007.

25. Kantarjian H, Pasquini R, Hamerschalk N, et al Dasatinib or high-dose imatinib for chronic -phase chronic myeloid leukemia after failure of first-line imatinib:a randomized Phase 2 trial. Blood 109: 5143-5150, 2007.

26. Shah NP, Kantarjian HM, Kim DW, et al. Intermittent target inhibition with dasatinib $100 \mathrm{mg}$ once daily preserves efficacy and improves tolerability in imatinib-resistant and -intolerant chronic phase chronic myeloid leukemia. J Clin Oncol 26: 3204-3212, 2008.

27. Brave M, Goodman V, Kaminskas E, et al. Sprycel for chronic myeloid leukemia and Philadelphia chromosome-positive acute lymphoblastic leukemia resistant to or intolerant of imatinib mesylate. Clin Cancer Res 14: 352-359, 2008.

28. Capdeville R, Krahnke R, Hatfield A, et al. report of an international expanded access program of imatinib in adults with Philadelphia chromosome positive leukemias. Annals of Oncology 19: 1320-1326, 2008.

29. Hocchaus A. Management of Bcr-abl positive leukemias with dasatinib. Expert Rev Anticancer Ther 7: 1529-1536, 2007.

30. Baccarani M, Rosti G, Castagnetti F, et al. Comparison of imatinib $400 \mathrm{mg}$ and $800 \mathrm{mg}$ daily in the front-line treatment of high-risk, Philadelphia-positive chronic myeloid leukemia: a European LeukemiaNet Study. Blood 113: 4497-504, 2009.

31. Hayran M, Koca E, Haznedaroglu IC, et al. Predicting chronic leukaemias from assessment of complete peripheral blood counts. J Int Med Res 34: 640-647, 2006.

32. Haznedaroglu I, Koca E. Imatinib mesylate and the management of chronic myeoid leukemia (CML). Turk J Haematol 22: 161-172, 2005.

\section{Correspondence}

Prof. Dr. Osman İlhan

Ankara Üniversitesi Tıp Fakültesi

Hematoloji Anabilim Dalı

Ankara / TÜRKIYYE

Tel: (+90.312) 4660860

Fax: (+90.312) 4660862

E-posta: oilhan@superonline.com 